\title{
Implications of Sex Hormone Receptor Gene Expression in the Predominance of Hepatocellular Carcinoma in Males: Role of Natural Products
}

\author{
Hanaa H Ahmed ${ }^{1 *}$, Wafaa Gh Shousha ${ }^{2}$, Aziza B Shalby ${ }^{1}$, Hatem A El-Mezayen ${ }^{2}$, \\ Nora N Ismaiel $^{3}$, Nadia S Mahmoud ${ }^{1}$
}

\begin{abstract}
The present study was planned to investigate the role of sex hormone receptor gene expression in the pathogenesis of hepatocellular carcinoma (HCC). Adult male Wistar rats were divided into seven groups. Group (1) was negative control. Groups (2), (5), (6), and (7) were orally administered with N-nitrosodiethylamine for the induction of HCC, then group (2) was left untreated, group (5) was orally treated with curcumin, group (6) was orally treated with carvacrol, and group (7) was intraperitoneally injected with doxorubicin, whereas groups (3) and (4) were orally administered only curcumin and carvacrol, respectively. The HCC group showed significant upregulation in the androgen receptor $(A R)$ and the estrogen receptor-alpha $(E R \alpha)$ gene expression levels in the liver tissue. On the contrary, HCC groups treated with either curcumin or carvacrol showed significant downregulation in AR and ER $\alpha$ gene expression levels in the liver tissue. In conclusion, the obtained data highlight that both AR and ER $\alpha$ but not estrogen receptor-beta (ERß) gene expression may contribute to the male prevalence of $\mathrm{HCC}$ induced in male rats. Interestingly, both curcumin and carvacrol were found to have a promising potency in alleviating the male predominating HCC.
\end{abstract}

Keywords: Hepatocellular carcinoma - male - androgen receptor - estrogen receptor - curcumin - carvacrol

Asian Pac J Cancer Prev, 16 (12), 4949-4954

\section{Introduction}

Hepatocellular carcinoma (HCC) incidence and mortality have globally increased over the last four decades (Abdelaziz et al., 2014; Zekri et al., 2015). Liver cancer is the fifth most common cancer in males, and the seventh most commonly diagnosed cancer in females (Gao et al., 2012; Zhong et al., 2014).

In fact, HCC has a remarkable increased predominance in males, with a male to female ratios averaging between 2:1 and 4:1 in most published series (Nordenstedt et al., 2010; Zekri et al., 2015). Not only males develop HCC more often than females, but once they develop it, they also die easier than females. In general, the prognosis for the disease is more benign in females than in males and women have a better survival and a reduced recurrence of the disease after the treatment (El-Serag et al., 2001). From all these evidences, the interest of some researchers has been focused since the 80 's on the possible importance of sex hormones in determining such preference for the male gender (Maria et al., 2002).

The expression and functional status of the androgen receptor (AR) and the estrogen receptor (ER) appear to play a significant role in the carcinogenesis of all hormones sensitive organs. The expression and activation of these receptors were also reported to be greatly increased in the liver tissues of male and female rodents during chemically induced liver carcinogenesis (Maria et al., 2002).

Curcumin, a natural polyphenol found in the dietary spice turmeric used traditionally in medicine in India and other Asian countries, has been demonstrated to have anticancer activity, including prevention of tumor initiation, promotion, metastasis, and angiogenesis in experimental animal models, against a wide range of tumor cells without promoting the development of side effects (Yallapu et al., 2013).

Carvacrol is a monoterpenic phenol found in the essential oils extracted from aromatic plants such as, thyme and oregano (Esiyok et al., 2004). Carvacrol is widely used as a food flavoring agent, a food preservative agent and a cosmetic ingredient. Recently, many studies have shown that carvacrol possess a variety of biological and pharmacological properties including antioxidant, antibacterial, antifungal, anticancer, anti-inflammatory and hepatoprotective activities (Suntres et al., 2015).

Our previous studies have documented the antitumor

${ }^{1}$ Hormones Department, Medical Research Division, National Research Centre, Dokki, Giza, Egypt, ${ }^{2}$ Chemistry Department, Faculty of Science, Helwan University, Cairo, Egypt; ${ }^{3}$ Molecular Genetics and Enzymology Department, Human Genetics and Genome Research, National Research Centre, Dokki, Giza, Egypt*For correspondence: Hanaaomr@yahoo.com 
efficacy of curcumin and carvacrol against HCC induced chemically in rats. The effect of these natural products was achieved via hindering the tumor cells proliferation, promoting apoptosis and inhibiting the angiogenesis (Ahmed et al., 2013; Ahmed et al., 2015).

The current study was constructed to evaluate the role of sex hormone receptors (AR and ER) gene expression in the pathogenesis of chemically induced hepatocellular carcinoma in male rats and shed light on the potential significance of curcumin and carvacrol in mitigating the male predominant HCC with special concern on their possible mechanisms of action.

\section{Materials and Methods}

\section{Chemicals and reagents}

N-nitrosodiethylamine (NDEA) (CAS no. 55-18-5), Curcumin (Cat\# C1386), and carvacrol (Cat\# 282197) were purchased from Sigma-Aldrich Chemicals Co. (St Louis, MO, USA). Doxorubicin was purchased from Pharmacia Italia S.P.A, Milan, Italy. All other chemicals used in the experiment were locally purchased (Egypt) and were of high analytical grade.

\section{Animals and experimental design}

This study was conducted on fifty six adult male Wistar rats weighing 180-200 g purchased from the animal house colony of the National Research Centre, Cairo, Egypt. The rats were kept under strict hygienic conditions and allowed to feed on a standard rodent chow and water. Rats were adapted to these conditions for two weeks before beginning the experiment. The animal experimental protocol was approved by the Ethical Committee for Medical Research, National Research Centre, Egypt (No. 12110).

After the acclimation period, the animals were randomly divided into seven groups with eight rats per group as follows: (1) Healthy rats served as a negative control group and were orally received $1-\mathrm{ml}$ vehicle solution (Tween-80 (1\%) in 0.9\% normal saline) /rat, five times a week during the whole experimental period (21 weeks); (2) HCC group, in which rats were orally administered NDEA with a dose of $20 \mathrm{mg} / \mathrm{kg}$ b.wt. , five times a week for six weeks, according to the modified method of Darwish and El-Boghdady (2011); (3) Curcumin control group, in which rats were orally treated with curcumin only (dissolved in Tween-80 (1\%) in $0.9 \%$ normal saline) with a dose of $100 \mathrm{mg} / \mathrm{kg}$ b.wt. (five days a week) for 15 weeks, as previously reported by Sreepriya and Bali (2005); (4) Carvacrol control group, in which rats were orally treated with carvacrol only (dissolved in Tween-80 (1\%) in saline) with a dose of $15 \mathrm{mg} / \mathrm{kg}$ b.wt. (five days a week) for 15 weeks, as previously reported by Jayakumar et al. (2012); (5) Curcumin-treated group, in which rats were orally treated with curcumin with a dose of $100 \mathrm{mg} / \mathrm{kg}$ b.wt. , five times a week for 15 weeks, following the administration of NDEA for six weeks, as previously reported by Sreepriya and Bali (2005); (6) Carvacrol-treated group, in which rats were orally treated with carvacrol with a dose of $15 \mathrm{mg} / \mathrm{kg}$ b.wt., five times a week for 15 weeks, following the administration of NDEA for six weeks, as previously reported by Jayakumar et al. (2012); and (7) Doxorubicin-treated group, in which rats were intraperitoneally injected with doxorubicin as a reference drug with a dose of $0.72 \mathrm{mg} / \mathrm{rat}$, which is equivalent to the human dose of $40 \mathrm{mg} / \mathrm{m}^{2}$, according to equation of Barnes and Paget (1965) once a week for 15 weeks, following the administration of NDEA for six weeks.

After the experimental period, rats were fasted overnight and sacrificed by cervical displacement under diethyl ether anesthesia, then the liver was dissected and snap-frozen immediately in the liquid nitrogen and stored at $-80^{\circ} \mathrm{C}$ for the gene expression analysis.

\section{Gene expression method}

RT-PCR analysis: The total RNA was extracted from the liver tissue of rats in each group using TRIzol reagent (Bioshop Canada Inc.). Isolated RNA was reverse transcribed into complementary DNA (cDNA) using Revert Aid first strand cDNA synthesis kit (Fermentas Co., USA). The subsequent PCR was performed using $5 \mu \mathrm{g}$ of cDNA in a final volume of 20 $\mu \mathrm{l}$ containing $10 \mathrm{x}$ PCR buffer, $10 \mathrm{mM}$ dNTPs, $5 \mathrm{U} / \mu \mathrm{l}$ of Taq DNA polymerase (Fermentas, USA), and $10 \mu \mathrm{M}$ of each specific primer. Glyceraldehyde 3 phosphate dehydrogenase (GAPDH) (Metabion-Germany) was used as internal control with primer sequences: forward, 5 CAAGGTCATCCATGACAACTTTG3', and reverse, 5 GTCCACCACCCTGTTGCTGTAG3. Primer sequences for androgen receptor (AR) (Metabion-Germany) were forward, 5 GTGTCGTCTCCGGAAATGTT3', and reverse, 5 'GGAATCAGGCTGGTTGTTGT3` according to Staub et al. (2005) published sequence, while primer sequences for $\mathrm{ER} \alpha$ (Metabion-Germany) were forward, 5 AGTGAAGCCTCAATGATGGG 3`and, reverse, 5 CAAAGATCTCCACCATGCCT3 according to Staub et al. (2005) published sequence and those for ER $\beta$ (Metabion-Germany) were forward, 5 'CTACTGAACGCGGTGACAGA3', and reverse, 5 CGTGTGAGCATTCAGCATCT3 according to Staub et al. (2005) published sequence. The PCR cycling was performed using a gradient thermal cycler (BioRad, USA) as follows: initial denaturation at $94^{\circ} \mathrm{C}$ for 5 minutes, followed by denaturation at $94^{\circ} \mathrm{C}$ for 30 seconds was done. Amplification was carried out using 35 cycles with an annealing temperature at $58^{\circ} \mathrm{C}$ for AR and GAPDH and at $55^{\circ} \mathrm{C}$ for $\mathrm{ER} \alpha$ and $\mathrm{ER} \beta$ for 30 seconds, followed by extension at $72^{\circ} \mathrm{C}$ for 1 minute and a final extension at $72^{\circ} \mathrm{C}$ for 8 minutes. The PCR products were separated on $2 \%$ agarose gel and visualized by the gel documentation system. The amplified products' size was determined by comparison to a DNA ladder (100 bp) (Fermentas, USA). All gene expression levels were semiquantified using LabImage analysis (LabImage 2.7.0, Kapelan $\mathrm{GmbH}$ ) software and were normalized against GAPDH gene expression.

\section{Statistical analysis}

All results were represented as the mean $+\mathrm{SE}$ of the mean. Data were analyzed by one-way analysis of variance (ANOVA) using the SPSS software program (version 
14.0; SPSS Inc., Chicago, IL, USA) followed by the least significant difference (LSD) to compare the significance between the groups. P-values $<0.05$ were considered statistically significant.

\section{Results}

\section{Gene expression results}

AR gene expression: As shown in Figure 1 and Table 1, the results showed that there was a significant overexpression of the AR gene $(\mathrm{p}<0.05)$ in the liver tissue of the HCC group (lane 2) compared with that in the negative control group (lane 1). The AR gene showed low expression levels in the liver tissue of rats in the curcumin control group (lane 6) and the carvacrol control group (lane 7). There was an insignificant change $(\mathrm{p}>0.05)$ in the AR gene expression level in the liver tissue of rats in curcumin or carvacrol control group compared with that in the negative control group. The AR gene expression level was shown to be significantly downregulated $(\mathrm{p}<0.05)$ in the liver tissue obtained from rats in the curcumin-treated group (lane 4 ) and in the liver tissue of rats in the carvacrol-treated group (lane 5) as compared to that in the untreated HCC group. Similarly, it was found to be significantly downregulated $(\mathrm{p}<0.05)$ in the liver tissue of rats in the doxorubicin-treated group(lane 3 ) as compared to that in the liver tissue of rats in the untreated HCC group.

\section{ERa gene expression}

As indicated in Figure 2 and Table 1, the results

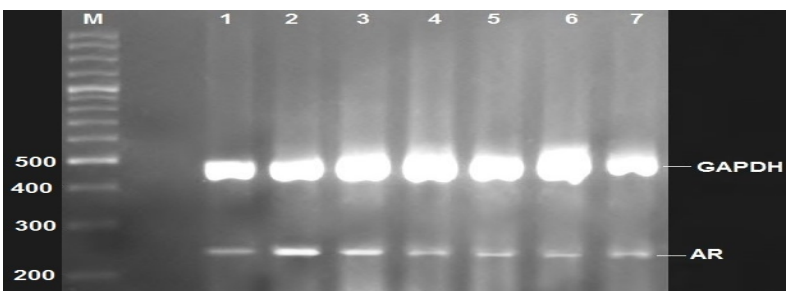

Figure 1. Agarose Gel Electrophoresis Shows AR mRNA Expression in the Liver Tissue by RT-PCR Analysis. GAPDH expression with 496 bp, AR expression with $266 \mathrm{bp}$. Negative control group (Lane 1), HCC group (Lane 2), doxorubicin-treated group (Lane 3), curcumin-treated group (Lane 4), carvacrol-treated group (Lane 5), curcumin control group (Lane 6), carvacrol control group (Lane 7). DNA ladder (100 bp) (Lane M)

Table 1. The Gene Expression Level of AR and ER $\alpha$ in the Liver Tissue of Rats in the Different Groups

\begin{tabular}{lcc}
\hline Groups & AR expression & ER $\alpha$ expression \\
\hline Negative control group & $0.4830 \pm 0.003$ & $0.1308 \pm 0.09506$ \\
HCC group & $0.9745 \pm 0.03907^{\mathrm{a}}$ & $0.5320 \pm 0.01504^{\mathrm{a}}$ \\
Doxorubicin-treated group & $0.6498 \pm 0.02064^{\mathrm{b}}$ & No expression \\
Curcumin-treated group & $0.2303 \pm 0.00862^{\mathrm{b}}$ & No expression \\
Carvacrol-treated group & $0.4110 \pm 0.00881^{\mathrm{b}}$ & No expression \\
Curcumin control group & $0.2325 \pm 0.02346$ & No expression \\
Carvacrol control group & $0.3473 \pm 0.02315$ & No expression \\
\hline
\end{tabular}

Values are expressed as the mean \pm standard error (SE) of mean for four samples/group; a: Significant change at $\mathrm{p}<0.05$ in comparison with the negative control group; b: Significant change at $\mathrm{p}<0.05$ in comparison with the HCC group; HCC hepatocellular carcinoma

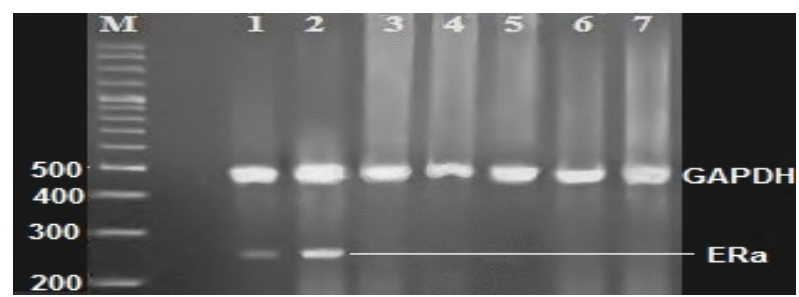

Figure 2. Agarose Gel Electrophoresis Shows ER $\alpha$ mRNA Expression in the Liver Tissue by RT-PCR Analysis. GAPDH expression with 496 bp, ER $\boldsymbol{\alpha}$ expression with 281 bp. Negative control group (Lane 1), HCC group (Lane 2), doxorubicin-treated group (Lane 3), curcumin-treated group (Lane 4), carvacrol-treated group (Lane 5), curcumin control group (Lane 6), carvacrol control group (Lane 7).DNA ladder (100 bp) (Lane M)

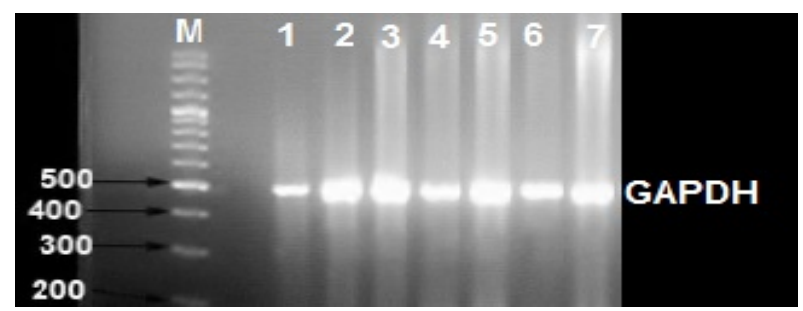

Figure 3. Agarose Gel Electrophoresis Shows ERß mRNA Expression in the Liver Tissue by RT-PCR Analysis. GAPDH expression with 496 bp, ER $\boldsymbol{\beta}$ expression with 255 bp. Negative control group (Lane 1), HCC group (Lane 2), doxorubicin-treated group (Lane 3), curcumin-treated group (Lane 4), carvacrol-treated group (Lane 5), curcumin control group (Lane 6), carvacrol control group (Lane 7). DNA ladder (100 bp) (Lane M)

revealed that there was a significant upregulation in the $E R \alpha$ gene expression $(\mathrm{p}<0.05)$ in the liver tissue of the HCC group (lane 2) compared with that in the liver tissue of the negative control group (lane 1). The ER $\alpha$ gene was not expressed in the liver tissue of rats in the curcumin control group (lane 6) and the carvacrol control group (lane 7). The ER $\alpha$ gene expression level was shown to be decreased to an undetectable level in the liver tissue obtained from rats in the curcumin-treated group (lane 4) and in the liver tissue of rats in the carvacrol-treated group (lane 5). Likewise, ER $\alpha$ gene expression was found to be decreased to undetectable level in the liver tissue of rats in the doxorubicin-treated group (lane 3).

\section{ER $\beta$ gene expression}

As illustrated in Figure 3, the results showed that $\operatorname{ER} \beta$ gene was not expressed in the liver tissue of rats in the negative control group (lane 1) as well as in that of the HCC group (lane 2). Similarly, there was no ER $\beta$ expression in the liver tissue of rats in the curcumin control group (lane 6) and the carvacrol control group (lane 7). ER $\beta$ expression was shown to be absent in the liver tissue obtained from rats in the curcumin-treated group (lane 4) and in the liver tissue of rats in the carvacrol-treated group (lane 5). Similarly, ER $\beta$ gene was not expressed in the liver tissue of rats in the doxorubicin-treated group (lane 3).

\section{Discussion}

Hepatocellular carcinoma was found to show 
significantly higher prevalence in males, an effect related to sex hormones ( $\mathrm{Li}$ et al., 2012). Liver is a hormonesensitive organ that was found to express estrogen receptors (ER) as well as androgen receptors (AR) in both male and female patients (Villa et al., 2002).

Androgen receptor (AR) is critical for the development and maintenance of the male sexual phenotype. It is a type of nuclear receptor that regulates the gene transcription when activated by the androgens (Heinlein and Chang, 2002).

The current study reveals a significant AR overexpression in the liver tissue of the HCC group. Indeed, these results are in line with those published by Eagon et al. (1996) who reported that the expression and activation of AR are greatly increased in the liver tissue of male and female rodents during the chemical induction of the liver carcinogenesis. Ma et al. (2008) reported that the AR expression is elevated in the liver of the male patients with HCC as compared to the healthy subjects. Also, this study shows that the loss of hepatic AR in mice bearing HCC resulted in the reduction of HCC incidence. Moreover, this study suggested that the AR signaling promotes hepatocarcinogenesis via the enhancement of the cellular oxidative stress and DNA damage as well as suppression of p53-mediated DNA damage/repairing system and cell apoptosis.

AR was shown to regulate the expression of transforming growth factor-beta 1 (TGF- $\beta 1$ ) through binding to the androgen response element on the TGF- $\beta 1$ gene promoter, suggesting that such activation might regulate the progression of $\mathrm{HCC}$ in both human and animal models (Villa ,2009).

Recently, Awuah and Monga (2012) have elegantly unveiled one of the mechanisms of sex-related disparity of HCC depending on the existing finding that AR and testosterone contribute to the HCC predominance in males. It was found that the presence of androgens in males engages AR to stimulate the cell cycle-related kinase (CCRK) expression. Then CCRK activates $\beta$-catenin signaling which in turn stimulates the expression of the epidermal growth factor receptor and cyclin-D1 thus promoting the cell proliferation. These authors also suggested a mechanism by which $\mathrm{Wnt} / \beta$-catenin signaling may cause tumor progression in males. $\beta$-catenin activation in males with HCC leads to high expression and activation of AR which in turn results in high CCRK expression that stimulates a vicious cycle of cell growth and proliferation.

The suggested mechanism for overexpression of AR in the HCC group in the present study is related to the inflammatory signaling associated with the chemical induction of HCC by NDEA. Naugler et al. (2007) stated that NDEA administration causes a greater increase in the serum interleukin-6 (IL-6) concentration in male mice. IL-6 has been found to induce the AR gene expression level and activity via mitogen activated protein kinase (MAPK) pathway in prostate cancer cells (Lin et al., 2001).

The present results show that curcumin treatment in HCC group significantly downregulated the AR gene expression level in the liver tissue. This result is in accordance with that of Nakamura et al. (2002) who reported that curcumin downregulates AR gene expression and activation in the prostate cancer cell lines. Curcumin was shown to inhibit the IL-6 production in human multiple myeloma cells (Bharti et al., 2003). Hence, the current study suggests that the downregulation of the AR gene expression level due to the treatment of the HCC group with curcumin may be attributed to the ability of curcumin to reduce IL-6 production.

The results of the current study have shown that carvacrol administration in the HCC group significantly downregulates the AR gene expression level in the liver tissue. This finding is in accordance with that of Alexander and Ekunwe (2012) who demonstrated that the treatment of the human prostate cancer cell (PC-3) with the aqueous extract of Ocimum gratissimum leaf decreases the AR gene expression level.

The suggested mechanism underlying the reduction of the AR gene expression level by carvacrol could be due to the significant reduction of IL-6 levels by carvacrol. Such effect might be occurred through the attenuation of the NF- $x$ B pathway by carvacrol (Aristatile et al., 2013) which in turn results in a reduction of IL-6.

The current results show that doxorubicin significantly downregulated the AR expression in the liver tissue of rats in the HCC group. This finding is in an agreement with that of Rokhlin et al. (2006) who stated that doxorubicin suppresses the AR gene expression in the prostate cancer cell line. The underlying mechanism for this action of doxorubicin is not known.

Two subtypes of estrogen receptor (ER), ER $\alpha$ and $\operatorname{ER} \beta$, have been identified in the human liver tissue (Moggs and Orphanides, 2001).

The present study demonstrates that the $\mathrm{ER} \alpha$ was significantly overexpressed in the liver tissue of rats in the HCC group, and expressed at a low level in that of the negative control group, whereas no expression of ER $\beta$ has been found in the liver tissue from the normal or the HCC group at all. These results are in an agreement with the previous results reported by Alvaro et al. (2000).

The roles of the ERs have been widely investigated in other cancers than hepatocellular carcinoma. For example, the mutated ER $\alpha$ expression is involved in the breast carcinogenesis (Hayashi and Yoshida, 2000), while the ER $\beta$ expression suppresses the breast cancer cell proliferation and tumor formation (Paruthiyil et al., 2004). Although the precise role of ER $\alpha$ in HCC is unknown (Huang et al., 2006), previous study of Waalkes et al. (2004) suggested that the underlying basis of ER $\alpha$ overexpression in the liver tissue of HCC-induced mice may be related to the hypomethylation of the ER $\alpha$ promoter which have been associated with the ER $\alpha$ activation.

The role of ER $\alpha$ in the regulation of MAPK cascade has been further studied in cell lines expressing ER $\alpha$. It was found that estrogen-bound ER $\alpha$ can rapidly activate the ERK and AKT signal transduction pathways leading to the cell cycle progression and inhibition of apoptosis (Acconcia et al., 2005).

P53 gene mutations occur in the late stages of hepatocarcinogenesis and have been found to be 
associated with the prognosis and survival of HCC patients (Malaguarnera et al., 2010). Several lines of evidence have suggested that p53 regulates the ER $\alpha$ expression (Angeloni et al., 2004) and downregulates ER $\alpha$-responsive genes by interfering with the binding of ER $\alpha$ to its response element (Jin et al., 2008). So, the mutation of $\mathrm{p} 53$ gene could result in overexpression of the ER $\alpha$ gene in HCC.

The current study shows that ER $\alpha$ gene expression was decreased to undetectable level in the liver tissue of the HCC group treated with curcumin. This result is supported by a previous study conducted by Shao et al. (2002) which revealed that curcumin decreases the expression of the ER transcript in ER-positive (MCF-7) human breast cancer cell line. Such effect may be as the result of the upregulation of wild-type of the p53 gene by curcumin, which is thought to downregulate ER $\alpha$ expression. Also, the study of Liontas and Yeger (2004) demonstrated that curcumin is found to upregulate the p53 gene expression level and induce its nuclear translocation in neuroblastoma.

The present study shows that carvacrol administration decreased the ER $\alpha$ gene expression to undetectable level in the liver tissue of HCC group. This inhibitory effect could be attributed to the induction of the p53 gene that is responsible for the reduction in the gene expression level of ER $\alpha$. Al-Dhaheri et al. (2013) found that the treatment of the breast cancer cell line (MDA-MB-231) with the Origanum majorana extract, known to contain carvacrol, results in downregulation of mutant p53 gene with consequent upregulation of the wild-type p53.

The present work demonstrates that the ER $\alpha$ gene expression was absent in the liver tissue of rats in the HCC group administered doxorubicin. This result is in accordance with that of Rusetskaya et al. (2009) which showed that upon culturing of MCF-7 cells with doxorubicin, a significant downregulation in the ER gene expression level is observed.

The observed inhibition of the ER $\alpha$ gene expression by doxorubicin may be due to activation of the p53 gene, which is known to downregulate ER $\alpha$. Liu et al. (2008) reported that doxorubicin produces a cytotoxic effect in $\mathrm{H} 9 \mathrm{c} 2$ cells and neonatal rat cultured cardiomyocytes, which is associated with the increased activation and nuclear translocation of $\mathrm{p} 53$.

However, further studies are needed to address the exact molecular mechanism underlying the downregulation of sex hormone receptors expression level by these natural products.

In conclusion, the current study emphasizes the principal role of both AR and ER $\alpha$ but not estrogen receptor-beta $(E R \beta)$ gene expression in the male predominance of HCC in male rats. Interestingly, both curcumin and carvacrol showed a great efficacy against HCC.

\section{References}

Abdelaziz AO, Elbaz TM, Shousha HI, et al (2014). Survival and prognostic factors for hepatocellular carcinoma: an egyptian multidisciplinary clinic experience. Asian Pac J
Cancer Prev, 15, 3915-20.

Acconcia F, Totta P, Ogawa S, et al (2005). Survival versus apoptotic 17beta-estradiol effect: role of ER alpha and ER beta activated non-genomic signaling. J Cell Physiol, 203, 193-201.

Ahmed HH, Shousha WG, Shalby AB, et al (2013). In vivo antitumor potential of carvacrol against hepatocellular carcinoma in rat model. World journal of pharmacy and pharmaceutical sciences, 2, 2367-96.

Ahmed HH, Shousha WG, Shalby AB, et al (2015). Curcumin: a unique antioxidant offers a multimechanistic approach for management of hepatocellular carcinoma in rat model. Tumor Biol, 36, 1667-8.

Al-Dhaheri Y, Eid A, Abu Qamar S, Attoub S, et al (2013). Mitotic arrest and apoptosis in breast cancer cells induced by Origanum majorana extract: upregulation of TNF- $\alpha$ and downregulation of survivin and mutant p53. Plos one, $\mathbf{8}$, 56649.

Alexander TC, Ekunwe SIN (2012). Investigating the molecular mechanism of inhibition of proliferation of human prostate cancer (PC-3) cells by fractionated Ocimum gratissimum (og) leaf extracts. 9thInternational symposium on recent advances in environmental health research (Poster). Jackson, USA, p.42.

Alvaro D, Alpini G, Onori P, et al (2000). Estrogens stimulate proliferation of intra-hepaticbiliary epithelium in rats. Gastroenterology, 119, 1681-91.

Angeloni SV, Martin MB, Garcia-Morales P, et al (2004). Regulation of estrogen receptor-alpha expression by the tumor suppressor gene p53 in MCF-7 cells. J Endocrinol, 180, 497-504.

Aristatile A, Al-Assaf AH, Pugalendi KV (2013). Carvacrol suppresses the expression of inflammatory marker genes in D-galactosamine-hepatotoxic rats. Asian Pac J Trop Med, 6, 205-11.

Awuah PK, Monga SP (2012). Cell cycle-related kinase links androgen receptor and $\beta$-catenin signaling in hepatocellular carcinoma: Why are men at a loss? Hepatology, 55, 970-4.

Barnes JM, Paget GE (1965). Mechanisms of toxic action. Prog Med Chem, 4, 18-38

Bharti AC, Donato N, Aggarwal BB (2003). Curcumin (diferuloylmethane) inhibits constitutive and IL-6-inducible STAT3 phosphorylation in human multiple myeloma cells. J Immunol, 171, 3863-71.

Darwish HA, El-Boghdady NA (2011). Possible involvement of oxidative stress in diethylnitrosamine induced hepatocarcinogenesis: chemopreventive effect of curcumin. $J$ Food Biochem, 37, 353-61.

Eagon PK, Elm MS, Epley MJ, et al (1996). Sex steroid metabolism and receptor status in hepatic hyperplasia and cancer in rats. Gastroenterology, 110, 1199-1207.

El-Serag HB, Mason AC, Key C (2001). Trends in survival of patients with hepatocellular carcinoma between 1977 and 1996 in the United States. Hepatology, 33, 62-5.

Esiyok D,Semih Ötles S, Akcicek E (2004). Herbs as a Food Source in Turkey. Asian Pac J Cancer Prev, 5, 334-9.

Gao J, Xie L, Yang W, et al (2012). Risk factors of hepatocellular carcinoma - current status and perspectives. Asian Pac J Cancer Prev, 13, 743-52.

Hayashi S, Yoshida T (2000). Regulation of ER (estrogen receptor) gene expression in the genesis and development of breast cancer. Nippon Rinsho, 58, 495-503.

Heinlein CA, Chang C (2002). Androgen receptor (AR) coregulators: an overview. Endocr Rev, 23, 175-200.

Huang E, Wu C, Lee S, et al (2006). Opposing action of estrogen receptors $\alpha$ and $\beta$ on tumor necrosis factor- $\alpha$ gene expression and Caspase-8-mediated apoptotic effects in HA22Tcells. 
Hanaa $H$ Ahmed et al Mol Cell Biochem, 287, 137-45.

Jayakumar S, Madankumar A,Asokkumar S, et al (2012). Potential preventive effect of carvacrol against diethylnitrosamineinduced hepatocellular carcinoma in rats. Mol Cell Biochem, 360, 51-60.

Jin W, Chen Y, Di GH, et al (2008). Estrogen receptor (ER) \{beta\} or p53 attenuates ER \{alpha\}-mediated transcriptional activation on the BRCA2 promoter. J Biol Chem, 283, 29671-80.

Li Z, Tuteja G, Schug J, Kaestner KH (2012). Foxa1 and Foxa2 are essential for sexual dimorphism in liver cancer. Cell, 148, $72-83$.

Lin D, Whitney MC, Yao Z, et al (2001). Interleukin-6 induces androgen responsiveness in prostate cancer cells through up-regulation of androgen receptor expression. Clin Cancer Res, 7, 1773-81.

Liontas A, Yeger H (2004). Curcumin and resveratrol induce apoptosis and nuclear translocation and activation of $\mathrm{p} 53$ in human neuroblastoma. Anticancer Res, 24, 987-98.

Liu J, Mao W, Ding B, Liang C (2008). ERKs/p53 signal transduction pathway is involved in doxorubicin-induced apoptosis in $\mathrm{H} 9 \mathrm{c} 2$ cells and cardiomyocytes. Am J Physiol Heart Circ Physiol, 295, 1956-65.

Ma W, Hsu C, Wu M, et al (2008). Androgen receptor is a new potential therapeutic target for the treatment of hepatocellular carcinoma. Gastroenterology, 135, 947-55.

Malaguarnera G, Giordano M, Paladina I, et al (2010). Serum markers of hepatocellular carcinoma. Dig Dis Sci, 55, 2744-55.

Maria ND, Manno M, Villa E (2002). Sex hormones and liver cancer. Mol Cell Endocrinol, 193, 59-63.

Moggs JG, Orphanides G (2001). Estrogen receptors: orchestrators of pleiotropic cellular responses. EMBO Rep, 2, 775-81.

Nakamura K, Yasunaga Y, Segawa T, et al (2002). Curcumin downregulates AR gene expression and activation in prostate cancer cell lines. Int J Oncol, 21, 825-30.

Naugler WE, Sakurai T, Kim S, et al (2007). Gender disparity in liver cancer due to sex differences in MyD88-dependent IL-6 production. Science, 317, 121-4.

Nordenstedt H, White DL, El-Serag HB (2010). The changing pattern of epidemiology in hepatocellular carcinoma. Dig Liver Dis, 42, 206-14.

Paruthiyil S, Parmar H, Kerekatte V, et al (2004). Estrogen receptor beta inhibits human breast cancer cell proliferation and tumor formation by causing a G2 cell cycle arrest. Cancer Res, 64, 423-8.

Rokhlin OW, Glover RB, Guseva NV, et al (2006). Mechanisms of cell death induced by histone deacetylase inhibitors in androgen receptor-positive prostate cancer cells. Mol Cancer Res, 4, 113-23.

Rusetskaya NV, Lukyanova NY, Chekhun VF (2009). Molecular profile and cell cycle in MCF-7 and mcf-7/Dox cells exposed to conventional and liposomal forms of doxorubicin. Exp Oncol, 31, 140-3.

Shao Z, Shen Z, Liu C, et al (2002). Curcumin exerts multiple suppressive effects on human breast carcinoma cells. Int $J$ Cancer, 98, 234-40.

Sreepriya M, Bali G (2005). Chemopreventive effects of embelin and curcumin against $\mathrm{N}$ - nitrosodiethylamine/ phenobarbitalinduced hepatocarcinogenesis in Wistar rats. Fitoterapia, 76, 549-55.

Staub C, Rauch M, Ferrière F, et al (2005). Expression of estrogen receptor ESR 1 and its $46-\mathrm{kDa}$ variant in the gubernaculums testis. Biol Reprod, 73, 703-12.

Suntres ZE, Coccimiglio J, Alipour M (2015). The bioactivity and toxicological actions of carvacrol. Crit Rev Food Sci
Nutr, 55, 304-18.

Villa E (2009). Androgen receptor alterations in hepatocarcinogenesis. Digest Liver Dis, 41, 632-3.

Villa E, Grottola A, Colantoni A, et al (2002). Hepatocellular carcinoma: role of estrogen receptors in the liver. Ann NY Acad Sci, 963, 37-45.

Waalkes MP, Liu J, Chen H, et al (2004). Estrogen signaling in livers of male mice with hepatocellular carcinoma induced by exposure to arsenic in utero. J Natl Cancer Inst, 96, 466-74.

Yallapu MM, Jaggi M, Chauhan SC (2013) Curcumin nanomedicine: a road to cancer therapeutics. Curr Pharm Des. 19, 1994-2010.

Zekri A, Youssef AS, Bakr YM, et al (2015). Serum biomarkers for early detection of hepatocellular. carcinoma associated with HCV infection in egyptian patients. Asian Pac J Cancer Prev, 16, 1281-7

Zhong C, Li H, Liu D, et al (2014). Clinical study of hepatectomy combined with jianpi huayu therapy for hepatocellular carcinoma. Asian Pac J Cancer Prev, 15, 5951-7 